\title{
A Case Report of Synovial Osteochondromatosis of the Knee Joint with neither Calcification nor a Synovial Lesion on Imaging
}

\author{
Taihei Go, Hideyuki Aoki*, Sou Ikata, Yoshiyasu Miyazaki, Keiji Hasegawa, Takashi Nakamura, \\ Kazuaki Tsuchiya \\ Department of Orthopedics, Toho University, Tokyo, Japan \\ Email: ^taiheigo@gmail.com
}

How to cite this paper: Go, T., Aoki, H., Ikata, S., Miyazaki, Y., Hasegawa, K., Nakamura, T. and Tsuchiya, K. (2016) A Case Report of Synovial Osteochondromatosis of the Knee Joint with neither Calcification nor a Synovial Lesion on Imaging. Open Journal of Orthopedics, 6, 351-356. http://dx.doi.org/10.4236/ojo.2016.612047

Received: November 15, 2016 Accepted: December 11, 2016 Published: December 15, 2016

Copyright $\odot 2016$ by authors and Scientific Research Publishing Inc. This work is licensed under the Creative Commons Attribution International License (CC BY 4.0).

http://creativecommons.org/licenses/by/4.0/

\begin{abstract}
Synovial osteochondromatosis is a rare, benign condition of unknown etiology in which the synovium undergoes metaplasia, leading to cartilaginous nodules that ultimately break free, mineralize, and even ossify. The most commonly involved joint is the knee. Typically, radiographs can be diagnostic and mineralized nodules are pathognomonic. In as many as one-third of cases, however, no calcification or ossification of the cartilage occurs in the early stage of the disease because mineralization is time-dependent. In such cases, gadolinium-enhanced MRI can be useful. Unmineralized nodules are typically peripherally enhanced because they are attached to and derive a vascular supply from the synovium. We experienced an unmineralized case of synovial osteochondromatosis of the right knee joint, in which imaging diagnosis was difficult. Neither calcification nor ossification was observed, but all nodules were released from the synovium as loose bodies and there was no vascular supply. Therefore, MRI did not show a typical appearance. These findings suggest that synovial osteochondromatosis should be considered as a differential diagnosis in a case in which unmineralized loose bodies without a synovial lesion are found in an imaging examination.
\end{abstract}

\section{Keywords}

Osteochondromatosis, Knee Joint, Calcification, Synovial Lesion

\section{Introduction}

Synovial osteochondromatosis is a rare, benign condition of unknown etiology in which the synovium undergoes metaplasia, leading to cartilaginous nodules that ulti- 
mately break free, mineralize, and even ossify. The most commonly involved joint is the knee. Patients may be asymptomatic or may present with pain, swelling, and limited range of motion. Recommended treatment involves arthroscopic or open removal of loose bodies with or without a synovectomy to prevent further articular and periarticular destruction and to remove symptoms [1]. Synovial osteochondromatosis is usually diagnosed based on imaging findings because each stage of the disease has a characteristic appearance on X-ray, CT and MRI. Generally plain radiograph can be diagnostic and mineralized nodules are pathognomonic. Here, we report a case of synovial in which we had difficulty making a diagnosis due to an atypical imaging appearance.

\section{Case Report}

The patient was a 23-year-old female who presented with a 6-month history of right knee pain. She had no history of trauma. Severity of pain had increased gradually, especially when climbing stairs. Soft swelling in the proximal part of the right anterior knee was pointed out by her local doctor. A soft tissue tumor was suspected and she was referred to our hospital for further examination and treatment.

Plain X-ray and CT showed neither calcification nor ossification in the knee joint (Figure 1). MRI showed a swollen suprapatellar bursa filled with synovial fluid. This fluid had a low signal intensity on T1-weighted images and a high toiso intensity on T2-weighted images. A close examination showed that the fluid was filled with multiple small nodules that showed a slightly lower signal intensity than synovial fluid on T2-weighted MRI. On T1-weighted gadolinium-enhanced MRI (Gd-DTPA), the wall of the suprapatellar bursa was peripherally enhanced. There was no sign of synovial hyperplasia. Multiple nodules in the synovial fluid showed no enhancement (Figure 2).

A needle biopsy was conducted for diagnosis. Pathologically, cartilaginous tissue with scarce chondrometaplasia was observed, indicating synovial osteochondromatosis. The multiple nodules in the synovial fluid were suspected to be unmineralized loose bodies of synovial osteochondromatosis, although these nodules did not show typical calcification and ossification. During arthroscopic surgery performed to remove these loose bodies, multiple white loose bodies were found in the joint space and partially on

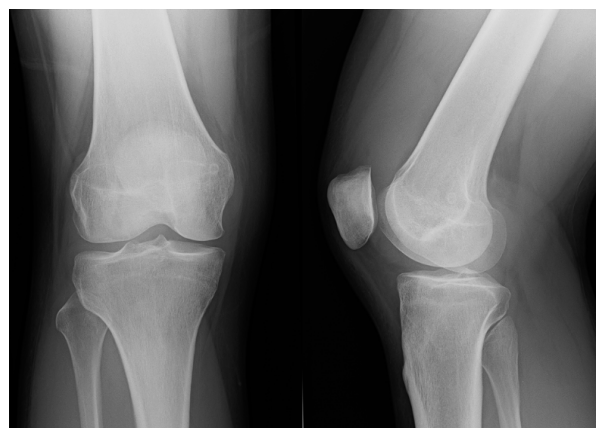

(a)

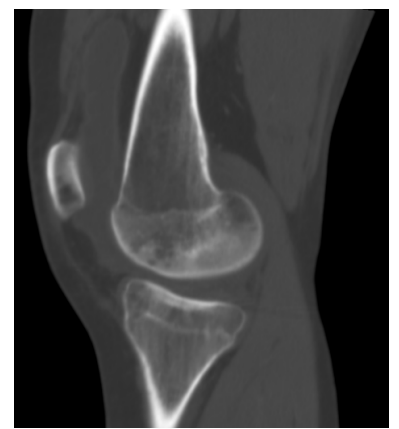

(b)

Figure 1. Anteroposterior and lateral radiograph (a) and sagittal CT (b) of the right knee, showing neither calcification nor ossification. 


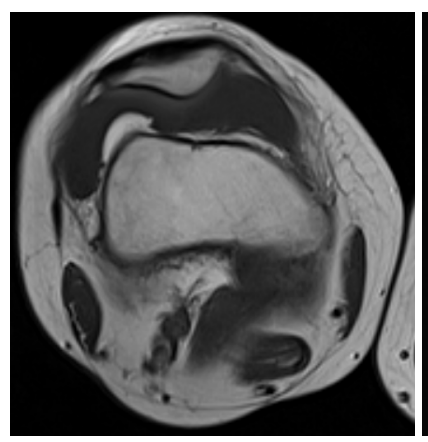

(a)

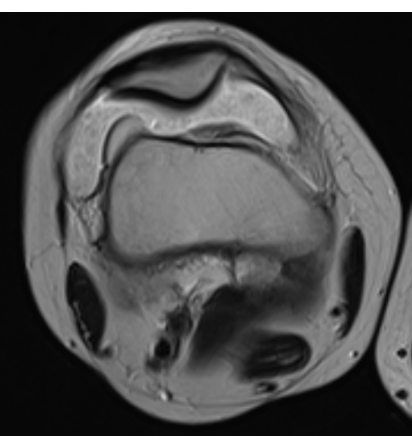

(b)

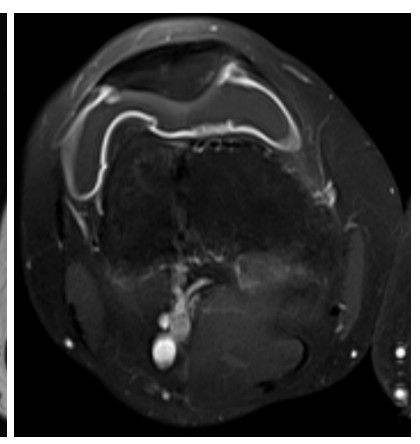

(c)

Figure 2. Transverse (a) T1-weighted MRI, (b) T2-weighted MRI and (c) T1-weighted gadolinium-enhanced MRI (Gd-DTPA), showing a swollen suprapatellar bursa filled with synovial fluid. This fluid was filled with multiple, small and vague nodules that had a slightly lower signal intensity than the fluid on T2-weighted images. Enhanced MRI showed peripheral enhancement of the bursa, but no enhancement of multiple nodules.

the surface of the synovium, but neither hyperplasia nor redness of the synovium was observed (Figure 3, Figure 4). The loose bodies were removed and partial synovectomy was performed in areas where cartilage was attached. The pathological appearance was the same as that in the needle biopsy samples. Neither hyperplasia nor infiltration of inflammatory cells was observed in the synovium. These macroscopic and pathological findings permitted definite diagnosis of synovial osteochondromatosis Milgram stage 3. After surgery, pain disappeared quickly. There was no recurrence at the recent follow up of 6 months after the surgery.

\section{Discussion}

Synovial osteochondromatosis is an uncommon arthropathy that affects various joints. Typically, it is a monoarticular disease that is most common in a large weight bearing joint, such as the knee (70\%) and hip (20\%) [1]. Synovial osteochondromatosis may be primary or secondary. Primary synovial osteochondromatosis has been reported 1 per 100,000 and occurs de novo in an otherwise normal joint. There is no clear link to the trauma history. Primary synovial osteochondromatosis affects males slightly more commonly than females and is most common in relatively young people of age 30 to 50 years [2]. The current case is a typical case of the primary form of the condition, except that the patient is female.

In 1977, Milgram classified synovial osteochondromatosis into three stages based on gross and pathological findings. In the first stage, cartilaginous nodules are attached to the synovial membrane and there are no loose bodies in the joint space. In the second stage, cartilaginous nodules are released from the proliferated synovial membrane as free bodies into the joint space. In the third stage, the synovial lesion becomes inactive and only loose bodies remain in the joint space [3].

Clinical diagnosis of synovial osteochondromatosis can be difficult because the presentation is non-specific. Pathological diagnosis can also be difficult, particularly in 


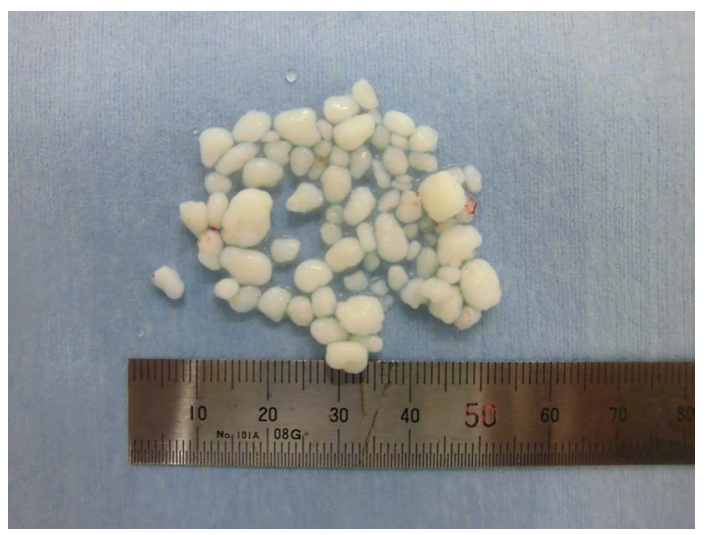

Figure 3. Macroscopic appearance of multiple loose bodies removed from the suprapatellar bursa.

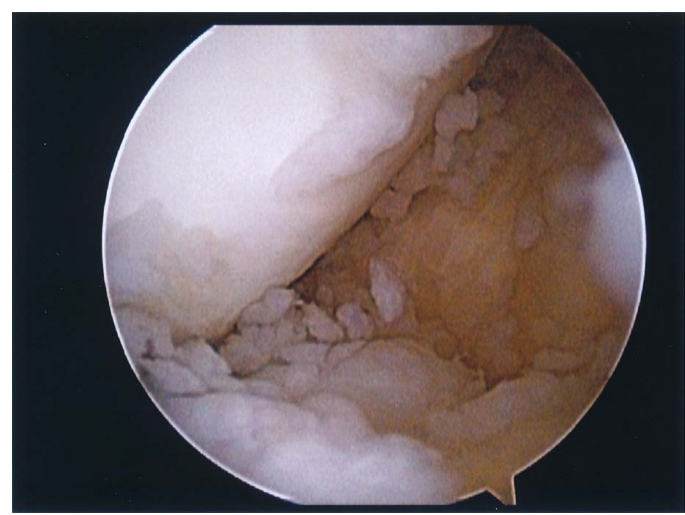

Figure 4. Arthroscopy showed multiple white loose bodies in the joint space and partially on the surface of the synovial membrane. Neither hyperplasia nor redness of the synovial membrane was observed.

the late stage, because the synovial lesion is inactive. However, the disease has a characteristic imaging appearance at each stage. Therefore, diagnosis is usually dependent on imaging findings. About $70 \%$ of cases of synovial osteochondromatosis can be diagnosed on radiographs because calcified nodules show pathognomonic features such as multifocal, spheroidal, articular or periarticular calcific densities with a uniform size. On CT, a soft tissue mass or water density is seen with multiple calcifications [2]. In other cases, however, there is no calcification or ossification of the cartilage because mineralization is time-dependent. In such cases, radiographic diagnosis is difficult, but MRI may be useful for diagnosis.

Kramer has described three subtypes (A, B and C) based on the MRI signal of the osteochondromal nodules. These subtypes roughly correlate with the Milgram 1, 2 and 3 pathological subtypes, respectively [4]. Unmineralized lesions (subtype A) account for $16 \%$ of cases. These nodules are difficult to distinguish from the synovial fluid/mass because both show low/intermediate signal intensity on T1-weighted MRI and high signal intensity on T2-weighted MRI. In such cases, T1-weighting gadolinium-enhanced MRI may be helpful in distinguishing nodules from synovial fluid. This is be- 
cause nodules are typically peripherally enhanced if they are attached to and derive a vascular supply from the synovium. Subtype B accounts for most cases (75\%). Nodules in this subtype give a low signal intensity on all MRI sequences due to calcification of cartilaginous nodules. Nodules in subtype C cases (9\%) contain fatty marrow and consequently are isointense to fat, with high and intermediate signals on T1- and T2weighted MRI, respectively. Signal suppression occurs on fat saturation sequences with a low signal rim on all sequences, similarly to bony cortex.

The current case was thought to be Kramer subtype A because neither calcification nor ossification was observed. However, gadolinium-enhanced MRI did not show the typical appearance for subtype A. Nodules were all released from the synovium as loose bodies and did not have a vascular supply, but were still atypically unmineralized. This is the reason why imaging diagnosis was difficult. Typically unmineralized nodules are observed in the early phase of the disease, such as Milgram stage 1, because mineralization is time-dependent. However, the definite diagnosis was Milgram stage 3 in this case because the synovial lesion was inactive and only loose bodies remained.

Milgram reported that new layers of tissue were formed on the outer surfaces of the loose bodies. At the same time, calcification could be observed radiographically and pathologically within the cartilage of the nidus and in deeper portions of the new layers of cartilage that formed around the nidus [5]. Therefore, calcified nodules typically have ring and arc patterns of mineralization or a target appearance (central focus with peripheral calcification) on CT [2]. However, in the current case all small and large loose bodies were unmineralized, even in the late phase, which suggests that mineralization had no relationship with the timing of disease progression.

Mizutani et al. described nonossified disease as synovial chondromatosis that differed from synovial osteochondromatosis [6], whereas Jeffreys et al. viewed these conditions as the same disease [7]. The correct position is unclear because the etiology and disease mechanism are unknown. In the case reported here, neither calcification nor ossification was present, even though synovial osteochondromatosis was in the third Milgram stage. This case suggests that synovial osteochondromatosis should be a differential diagnosis for unmineralized loose bodies that do not show typical MRI features, such as for nodules of Kramer subtype A.

\section{Conclusion}

Synovial osteochondromatosis should be included as a differential diagnosis in a case with unmineralized loose bodies without a synovial lesion in an imaging examination.

\section{Consent}

The patient gave informed consent to submit this case study for publication.

\section{Competing Interests}

The authors declare that there is no conflict of interest regarding the publication of this paper. 


\section{References}

[1] Neumann, J.A., Garrigues, G.E., Brigman, B.E., et al. (2016) Synovial Chondromatosis. Journal of Bone and Joint Surgery, 4, 1-7. https://doi.org/10.2106/jbjs.rvw.0.00054

[2] McKenzie, G., Raby, N. and Ritchie, D. (2008) A Pictorial Review of Primary Synovial Osteochondromatosis. European Society of Radiology, 18, 2662-2669. https://doi.org/10.1007/s00330-008-1024-8

[3] Milgram, J.W. (1977) Synovial Osteochondromatosis. Journal of Bone and Joint Surgery, 59-A, 792-801.

[4] Kramer, J., Recht, M., Deely, D.M., et al. (1993) MR Appearance of Idiopathic Synovial Osteochondromatosis. Journal of Computer Assisted Tomography, 17, 772-776. https://doi.org/10.1097/00004728-199309000-00020

[5] Milgram, J.W. (1977) The Development of Loose Bodies in Human Joints. Clinical Orthopedics and Related Research, 124, 292-303. https://doi.org/10.1097/00003086-197705000-00040

[6] Mizutani, A., et al. (1984) Synovial Osteochondromatosis and Chondromatosis. Clinical Orthopedic Surgery, 35, 151-158. (In Japanese).

[7] Jeffreys, T.E. (1967) Synovial Chondromatosis. Journal of Bone and Joint Surgery, 49-B, 530-534.

Submit or recommend next manuscript to SCIRP and we will provide best service for you:

Accepting pre-submission inquiries through Email, Facebook, LinkedIn, Twitter, etc. A wide selection of journals (inclusive of 9 subjects, more than 200 journals)

Providing 24-hour high-quality service

User-friendly online submission system

Fair and swift peer-review system

Efficient typesetting and proofreading procedure

Display of the result of downloads and visits, as well as the number of cited articles Maximum dissemination of your research work

Submit your manuscript at: http://papersubmission.scirp.org/

Or contact ojo@scirp.org 